\title{
Long-term remission of steroid-resistant Graves' orbitopathy after administration of anti-thymocyte globulin
}

\author{
Maria Świerkot ${ }^{1}$, Grażyna Kulawik1, Monika Sarnat-Kucharczyk², Krystyna Jagoda ${ }^{3}$, Ewa Mrukwa-Kominek², \\ Jerzy Chudek \\ ${ }^{1}$ Endocrinology Unit, Department of Internal Medicine and Oncological Chemotherapy, Faculty of Medical Sciences in Katowice, \\ Medical University of Silesia, Katowice, Poland \\ ${ }^{2}$ Department of Ophthalmology, Faculty of Medical Sciences in Katowice, Medical University of Silesia, Katowice, Poland \\ ${ }^{3}$ Department of Haematology and Bone Marrow Transplantation, Faculty of Medical Sciences in Katowice, Medical University \\ of Silesia, Katowice, Poland
}

Key words: Graves' orbitopathy; anti-thymocyte globulin; dysthyroid optic neuropathy

Most cases of Graves' orbitopathy (GO) are benign and require no special treatment. In the active moderate-to-severe lesion, constituting 5-6\% of cases, according to EUGOGO guidelines, an intravenous course of corticosteroids is the first-choice treatment, effective in about $70-80 \%$ of cases. The management of patients who are refractory to corticosteroid therapy is a major challenge and includes repeated courses of corticosteroids, orbital radiotherapy, cyclosporin A, and rituximab [1]. $\mathrm{CD} 4+$ cell infiltrates in orbital tissues play a central role in the molecular pathways leading to proliferation and differentiation of orbital fibroblast and the secretion of hyaluronic acid and the adipogenesis. GO patients are characterised by a low number of circulating Treg cells among peripheral blood mononuclear cells (PBMCs) with high CD4/CD8 ratios and abnormal cytokine expression [2]. In vitro, incubation of PBMCs obtained in GO patients with rabbit anti-thymocyte globulin (rATG) for $24 \mathrm{~h}$ substantially enhanced the expression of Treg cell markers FoxP3 and $\mathrm{CD}^{+}{ }^{+} \mathrm{CD} 4{ }^{+} \mathrm{CD} 25^{+} \mathrm{CD} 127^{\text {low }}$ [2].

Thymoglobulin (rATG) is a polyclonal rabbit antibody that causes T-cell depletion, used in the induction after kidney transplantation (KTx) and treatment of acute rejection. In addition, it was shown that ATG in vitro can induce apoptosis of naive plasma B cells and plasma cells [3], inhibit the secondary immune response by memory $\mathrm{B}$ cells via $\mathrm{T}$-cell modulation, and induce regulatory $\mathrm{T}$ cells during immune reconstitution [4]; thereby, it may suppress B cells and production of antibodies.
A 47-year-old woman with a 25-year history of Graves-Basedow disease, after subtotal strumectomy, two courses of radioiodine therapy, on thyroxine substitution, developed bilateral GO (conjunctival oedema, double vision, worsening of visual acuity). During glucocorticoid therapy (after 3-4 courses) according to the EUGOGO protocol, the patient developed symptomatic optic neuropathy treated with radiotherapy (20 Gy in 10 fractions) with continuation of methylprednisolone to a total dose $11 \mathrm{~g}$ with subsequent ineffective 14-week therapy with cyclosporin A. In July 2018, after obtaining acceptance of the therapy with rATG by the Bioethics Committee, we offered an experimental therapy with thymoglobulin (two doses of $1.5 \mathrm{mg} / \mathrm{kg}$ ) with pretreatment with methylprednisolone 250 and $125 \mathrm{mg}$, paracetamol, and clemastine.

The clinical improvement in GO where noted at six-week examination and was maintained a year after rATG administration (Tab. 1). There was a significant improvement in the patients' clinical status, both subjective (GO-QOL EUGOGO questionnaire) and in the ophthalmologic tests: decrease in CAS from $5 / 7$ to $0 / 7$, subsiding of diplopia, improvement of best-corrected distance visual acuity - BCDVA (from 0.5 to 0.7 right eye $-\mathrm{RE}$ and from 0.5 to 0.9 left eye - LE), and colour vision recovery assessed with Ishihara colour plates (from 11/16 to 16/16 RE and 10/16 to 16/16 LE). Improvement was noted in the NOSPECS scale (from 2-b, 4-c, 6-a to 2-0, 4-b, 6-0), Donaldson's ophthalmopathy index (from 6/15 to 3/15), and Octo- 


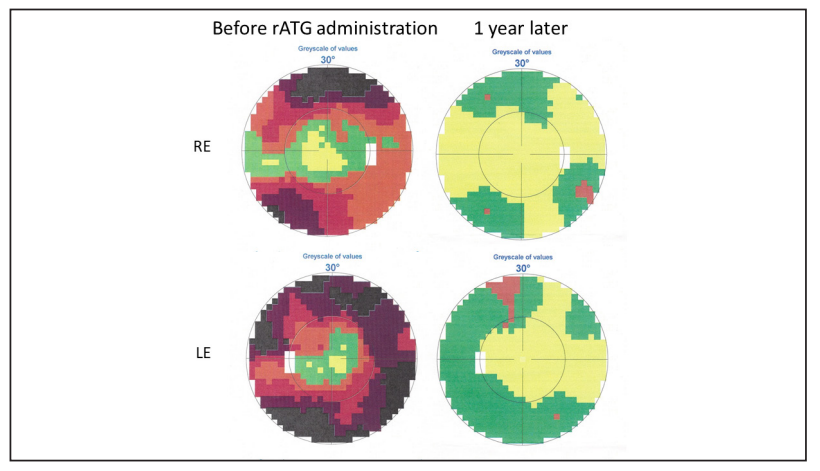

Figure 1. Octopus static visual field of the right (RE) and left (LE) eyes before rATG administration and after the one-year follow-up period

pus 1-2-3 static perimetry (Haag Streit, Switzerland), with complete reduction of absolute scotomata and decrease in relative scotomata (Fig. 1) and VEP Pattern, both in latency, which decreased (P100 latency after stimulation with $1^{\circ}$ normalized and were delayed to $105 \%$ after stimulation with $15^{\prime}$ ), and amplitude, which increased (Tab. 1). In addition, there was only a transient decrease in TRAb titre and persistent improvement in CD4/CD8 ratio of peripheral blood T lymphocytes.

The presented case shows that patients with steroid-resistant GO may benefit from rATG therapy and that the obtained clinical remission is related to the long-lasting change in CD4 to CD8 ratio of peripheral blood T lymphocytes without disappearance of TRAb production. Our finding is not in line with the unique observation of the resolution of GO shortly after induction therapy with rATG $(1.5 \mathrm{mg} / \mathrm{kg} /$ dose for five doses) with a triple immunosuppressive regimen (including glucocorticoids) in a kidney transplant recipient previously untreated for GO. The clinical improvement, in this case, was followed by the disappearance of TRAb after the procedure [5]. It should be stressed that in our patient glucocorticoid therapy, as well as RTH, were ineffective, and the available therapeutic options were exhausted.

Severe dysthyroid optic neuropathy (DON) in the course of GO is a sight-threatening complication [6]. In some individuals tension and lack of laxity of orbital septum prevent the eye globe from self-decompressing, resulting in severe DON, regardless of slight or no exophthalmos. This situation was present in our patient, whose colour vision loss and visual field loss were severely affected by compression neuropathy. A year after the rATG administration we observed significant improvement in functional visual tests, which can be explained by optic nerve decompression.

Therefore, we think that therapy with Thymoglobulin may be useful in the management of severe
Table 1. Evolution of clinical findings during a year after thymoglobulin administration in a patient with Graves' ophthalmopathy

\begin{tabular}{|c|c|c|c|c|c|}
\hline & \multicolumn{2}{|c|}{ Before rATG } & 12 weeks & \multicolumn{2}{|c|}{ One year } \\
\hline $\begin{array}{l}\text { Clinical } \\
\text { symptoms }\end{array}$ & \multicolumn{2}{|c|}{$\begin{array}{l}\text { Diplopia in } \\
\text { every direction, } \\
\text { abnormal acuity } \\
\text { and colour } \\
\text { vision }\end{array}$} & $\begin{array}{l}\text { Without diplopia, } \\
\text { significant } \\
\text { improvement } \\
\text { of visual acuity } \\
\text { and colour vision }\end{array}$ & \multicolumn{2}{|c|}{$\begin{array}{l}\text { Periodic } \\
\text { slight diplopia } \\
\text { in every } \\
\text { direction }\end{array}$} \\
\hline TRAb [IU/L] & \multicolumn{2}{|c|}{$>40$} & $>40$ & \multicolumn{2}{|c|}{$>40$} \\
\hline CD4/CD8 ratio & \multicolumn{2}{|c|}{3.0} & 1.5 & \multicolumn{2}{|c|}{1.8} \\
\hline DBCVA & \multicolumn{2}{|c|}{$\begin{array}{l}\text { RE } 0.5 \\
\text { LE } 0.5\end{array}$} & $\begin{array}{l}\text { RE } 0.8 \\
\text { LE } 0.9 \\
\end{array}$ & \multicolumn{2}{|c|}{$\begin{array}{l}\text { RE } 0.7 \\
\text { LE } 0.9\end{array}$} \\
\hline $\begin{array}{l}\text { Exophthalmometry } \\
\text { (Hertl) }\end{array}$ & \multicolumn{2}{|c|}{$\begin{array}{l}\text { RE } 16 \mathrm{~mm} \\
\text { LE } 18 \mathrm{~mm}\end{array}$} & $\begin{array}{l}\text { RE } 16 \mathrm{~mm} \\
\text { LE } 18 \mathrm{~mm} \\
\end{array}$ & \multicolumn{2}{|c|}{$\begin{array}{l}\text { RE } 16 \mathrm{~mm} \\
\text { LE } 18 \mathrm{~mm}\end{array}$} \\
\hline Donaldson & \multicolumn{2}{|c|}{$6 / 15$} & $1 / 15$ & \multicolumn{2}{|c|}{$3 / 15$} \\
\hline CAS & \multicolumn{2}{|c|}{$5 / 7$} & $1 / 7$ & \multicolumn{2}{|c|}{$1 / 7$} \\
\hline NOSPECS & \multicolumn{2}{|c|}{$\begin{array}{c}\text { 2-b, 3-0, 4-c, } \\
5-0,6-a\end{array}$} & $\begin{array}{c}\text { 2-a, 3-0, 4-0, } \\
5-0,6-0\end{array}$ & \multicolumn{2}{|c|}{$\begin{array}{c}2-a, 3-0 \\
4-b, 5-0,6-0\end{array}$} \\
\hline $\begin{array}{l}\text { Ishihara Colour } \\
\text { Plates }\end{array}$ & \multicolumn{2}{|c|}{$\begin{array}{l}\text { RE 11/16 } \\
\text { LE 10/16 }\end{array}$} & $\begin{array}{l}\text { RE 15/16 } \\
\text { LE 15/16 }\end{array}$ & \multicolumn{2}{|c|}{$\begin{array}{l}\text { RE 16/16 } \\
\text { LE 16/16 }\end{array}$} \\
\hline $\begin{array}{l}\text { PVEP } \\
1^{\circ}\end{array}$ & $\mathrm{RE}$ & & & $\mathrm{RE}$ & \\
\hline $\begin{array}{l}\text { P100 } \\
\text { N75-P100 }\end{array}$ & $\begin{array}{l}116 \\
6.3\end{array}$ & $\begin{array}{l}118 \\
8.3\end{array}$ & & $\begin{array}{l}110 \\
9.0\end{array}$ & $\begin{array}{l}109 \\
8.9\end{array}$ \\
\hline $\begin{array}{l}15^{\prime} \\
\text { P100 } \\
\text { N75-P100 }\end{array}$ & $\begin{array}{r}136 \\
6.9\end{array}$ & $\begin{array}{l}128 \\
4.8\end{array}$ & & $\begin{array}{l}130 \\
9.9\end{array}$ & $\begin{array}{l}130 \\
10.1\end{array}$ \\
\hline
\end{tabular}

CAS - Clinical Activity Scale; LE — left eye; MD — mean defect;

MS - mean sensitivity; PVEP — pattern visual evoked potentials; RE — right eye; Classification of Graves' ophthalmopathy (NOSPECS): 0 — no signs or symptoms; 1 - only signs, no symptoms; 2 - soft-tissue involvement; 3 - proptosis; 4 - extraocular muscle involvement; 5 - corneal involvement; 6 - sight loss

steroid-resistant GO. The effectiveness of this new therapy requires a larger number of observations.

\section{Acknowledgements}

The study was funded by the Medical University of Silesia in Katowice (grant number KNW-1-075/N/8/K).

\section{References}

1. Bartalena L, Baldeschi L, Boboridis K, et al. European Group on Graves' Orbitopathy (EUGOGO). The 2016 European Thyroid Association/European Group on Graves' Orbitopathy Guidelines for the Management of Graves' Orbitopathy. Eur Thyroid J. 2016; 5(1): 9-26, doi: 10.1159/000443828, indexed in Pubmed: 27099835.

2. Kahaly GJ, Shimony O, Gellman YN, et al. Regulatory T-cells in Graves' orbitopathy: baseline findings and immunomodulation by anti-T lymphocyte globulin. J Clin Endocrinol Metab. 2011; 96(2): 422-429, doi: 10.1210/jc.2010-1424, indexed in Pubmed: 21147887.

3. Zand MS, Vo T, Huggins J, et al. Polyclonal rabbit antithymocyte globulin triggers B-cell and plasma cell apoptosis by multiple pathways. Transplantation. 2005; 79(11): 1507-1515, doi: 10.1097/01. tp.0000164159.20075.16, indexed in Pubmed: 15940039.

4. Gurkan S, Luan Y, Dhillon N, et al. Immune reconstitution following rabbit antithymocyte globulin. Am J Transplant. 2010; 10(9): 2132-2141, doi: 10.1111/j.1600-6143.2010.03210.x, indexed in Pubmed: 20883548.

5. Lee Y, Butani L, Glaser N, et al. Resolution of Graves' disease after renal transplantation. Pediatr Transplant. 2016; 20(4): 590-593, doi: 10.1111/petr.12709, indexed in Pubmed: 27106887.

6. Blandford AD, Zhang D, Chundury RV, et al. Dysthyroid optic neuropathy: update on pathogenesis, diagnosis, and management. Expert Rev Ophthalmol. 2017; 12(2): 111-121, doi: 10.1080/17469899.2017.1276 444, indexed in Pubmed: 28775762. 